\title{
Dynamic Behavior of A Full-Scale Wind Turbine Tower Under Seismic Loading
}

\author{
Ghada N. Saudi, Boshra Aboul-Anen Eltaly, Mostafa Mahmoud Abo El-khier
}

\begin{abstract}
This paper presents the dynamic investigation of an existing wind turbine tower. Both experimental and numerical analyses were performed to assess the structural response of the tower under seismic load. Field ambient vibration test was applied to identify the actual dynamic properties experimentally. A vibration based finite element model was built in ANSYS to conduct the seismic response analysis. The tower shown to survive moderate earthquakes as it is located in Zafarana wind farm in Egypt, a zone lies by the red sea known for its historical seismic activity.
\end{abstract}

Keywords-Wind turbine tower, modal analysis, finite element model, seismic response analysis.

\section{Introduction}

The largest wind farm in Egypt was constructed in 20012010, Zafarana wind farm hosts 545 MW of grid connected wind power, to become the largest wind farm in Africa and the Middle East. The Zafarana Wind Farm is located $120 \mathrm{~km}$ south of Suez on the Red Sea. It is planned to supply the electricity grid with 42,000 million $\mathrm{kWh}$ over its life time that in turn will save 10 million tons oil equivalent and will abate the emission of greenhouse gases. The Wind farm is considered a vital asset producing 12\% of Egypt's electricity. The Egyptian government's target is that $20 \%$ of the country's electricity should come from renewable sources by 2020. The Zafarana farm consists of eight farms, the first constructed one constitutes of fifty Nordex N43 wind turbine towers as shown in Fig. 1. The installed modern wind turbine systems typically consist of three basic components (rotor, nacelle and tower) as shown in Fig. 2. The rotor for a typical utility-scale wind turbine includes three high-tech blades, a hub, and a spinner. The nacelle of a wind turbine contains components of the wind turbine such as the gearbox, generator, mainframe, etc. The nacelle and generator are mounted on top of a high tower to allow the blades to take advantage of the best winds. Seismic loading of wind turbines is being addressed in guidelines for wind turbine design. The Main guidelines implement direct

Ghada N. Saudi

Associate professor, Structures and Metallic Constructions Research Institute

Housing and Building National Research Center

Egypt

Boshra Aboul-Anen Eltaly

Associate professor, Civil Engineering Department, Faculty of Engineering, Menoufia University

Egypt

Mostafa Mahmoud Abo El-khier

Assistant Lecturer, Civil Engineering Department, Faculty of Engineering, Menoufia University

Egypt instructions for seismic loading and its risk aspects of wind turbines: Guidelines for Design of Wind Turbines (Riso, 2002) [1]; Guideline for the Certification of Wind Turbines (GL, 2003) [2]; and IEC 61400-1 Ed.3: Wind turbinesPart 1: Design requirements (IEC, 2005) [3].

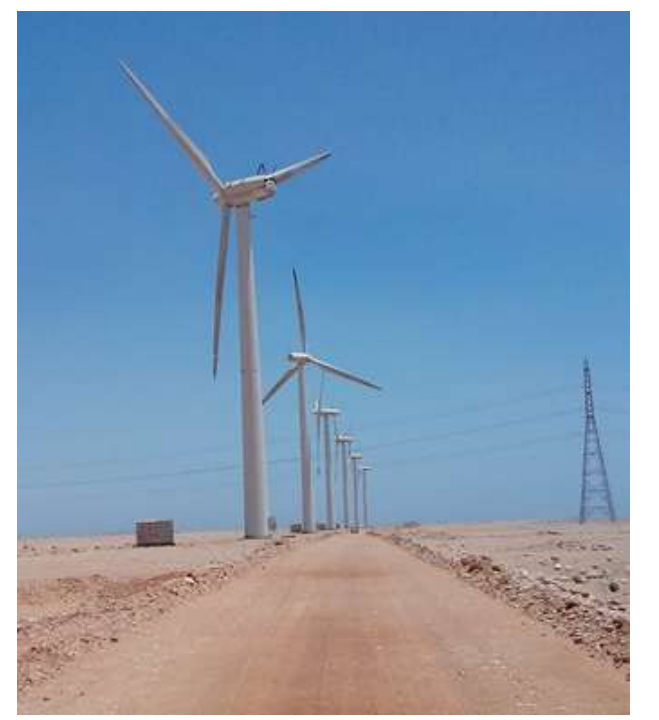

Fig. 1 Nordex wind turbine towers at Zafarana wind farm.

Special standard is the Canadian standard for wind turbine design (CSA, 2008) [4] instructing designers how to obtain seismic loads, design spectral accelerations, and seismic design data. Numerical modelling of wind turbine structures has been introduced in design guidelines as simplified models to determine the first natural period. The given procedures use the first natural period to extract the design response acceleration from a design response spectrum.

Finite element method is not usually utilized for modelling the turbine due to computational complexity, but instead a limited-degree-of-freedom modal model is used (Bossanyi, 2003) [5] considering seismic loading of wind turbines focused on loading of the tower based on simplified models that lumped the nacelle and rotor as a point mass (Bazeos et al., 2002; Lavasas et al., 2003) [6:7].

A study considering both earthquake and wind loads was published by Kiyomiya et al. (2002) [8]. A simplified beamcolumn model with a lumped mass for the nacelle and rotor mass at the hub height with an assumed equivalent viscous damping of $2 \%$ is used to simulate the turbine structure. It is concluded that the turbine has sufficient strength to resist the earthquake without damage. Recent experimental studies were published to investigate the seismic response of full scale wind turbine structures. A full-scale shake table test was conducted to obtain the seismic response characteristics of a $23 \mathrm{~m}$ high wind turbine. Experimental modal analysis had been performed in order to obtain the dynamic parameters of the wind turbine tower. Based on the test 


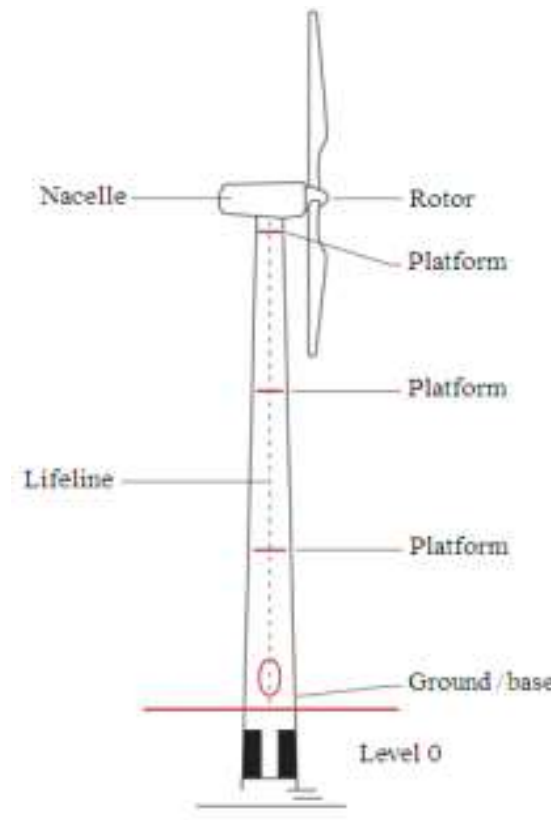

Fig. 2 Typical wind turbine system components.

results, two calibrated beam-column finite element models were developed and updated. The first model consisted of a vertical column of elements with a lumped mass at the top that accounts for the nacelle and the rotor. Additional beamcolumn elements were included in the second model to explicitly represent the geometric configuration of the nacelle and the rotor. The experimental test and finite element model results showed a good agreement and proved useful insights. The second model simulations were conducted using a set of ground motions from California earthquakes. These motions were all recorded at ground level in relatively stiff structures (Prowell et al., 2009) [9]. In 2011, Arasu et al. [10] applied a finite element seismic analysis during the design of an almost $76 \mathrm{~m}$ high steel tower supporting a 1.6 MW wind turbine with a horizontal power transmission axle. The main supporting tower of the wind turbine was assembled by thin-wall cylindrical and conical parts of varying diameters and wall thicknesses with circular stiffeners. The nacelle and rotor masses were added as concentrated mass elements at the hub height of $78 \mathrm{~m}$. A modal analysis was carried out to obtain the free vibration modes and frequencies of the turbine tower. Seismic response analysis was then performed by applying the ground motion excitations \& acceleration was applied directly to the structure along the vertical direction. The modal damping for the structure was computed and applied along with the acceleration response spectra. From the results, the stresses at the door level showed the highest value.

In 2012, Myers et al. [11] discussed several pertinent issues unique to assessing seismic wind turbine vulnerability and also presented finite element analysis results on the fragility of one particular wind turbine tower as a function of ground motion intensity and frequency content. A nonlinear finite element model of an $80 \mathrm{~m}$ tall $2.4 \mathrm{MW}$ turbine tower was developed. The nonlinear model was constructed using the structural engineering analysis program SAP2000, which was validated against a more complex finite element model that was built using ABAQUS. The modal was subjected to nonlinear dynamic analyses utilizing suites of ground motions representing near-field conditions, soft-soil conditions, and standard conditions. The fragility of one particular $80 \mathrm{~m}, 2.4 \mathrm{MW}$ wind turbine was shown to be the highest for soft soil ground motions and the lowest for firm soil ground motions with pulse-like ground motions having an intermediate fragility. Other studies considered the soil structure interaction in the seismic response analysis of wind turbine structures. In 2012, Hongwang [12] presented a seismic response model including soil-structure interaction (SSI) and P- $\Delta$ effecting under both horizontal and vertical earthquake actions. A finite element model had been developed for the wind turbine tower as multi-degree of freedom system and soil interaction as a rigid thickness plate with radius moment of inertia and mass. The rigid foundation-soil interaction is modeled by the spring-dampermass model. The proposed model was applied to $1.65 \mathrm{MW}$ and $3 \mathrm{MW}$ wind turbines. The two wind turbines were analyzed under six historical earthquake records both horizontal and vertical motions. The analysis of the results revealed that that including SSI produces a decrease in natural frequencies.

In 2013, Taddei and Meskouris [13] estimated the seismic response of a soil-turbine system and involved a 1.5MW, 3-blade wind turbine, grounded on a layered half space. The wind turbine system was modeled by means of Finite Element Method (FEM). The tower was simulated by a shell element. The rotor blades, the nacelle and the gear box were idealized as a concentrated mass point at the top of the tower. The soil was represented by a soft clay layer over a harder clay half space and modeled by six uncoupled springs, one along each of the six degrees of freedom. The results of the FEM were obtained before applying seismic spectra. The design spectra were created according to the Turkish national annex of the EC8 and applied to the far end of the springs. In parallel, the same investigation was performed with a more accurate method, a coupling between finite element and Boundary Element Method (BEM). The FEM gave a good modeling for the seismic behavior.

The Zafarana wind farm is located in an active seismic zone along the west side of the Gulf of Suez. Accordingly, seismic risk assessment is demanded for studying the structural integrity of wind towers under expected seismic hazard events. In the context of ongoing joint US- Egypt research "Seismic risk assessment of wind turbine towers in Zafarana wind farm Egypt", the wind turbine tower of Nordex N43 type was studied to investigate its dynamic behavior under seismic loads. Field ambient vibration testing was applied to capture the modal properties of the existing tower. Measurements were recorded in the main horizontal directions allowing the identification of all bending modes of the full-scale tower. The numerical model in ANSYS [14] was validated using the experimental results. Seismic response spectrum analysis was applied to study the structural response of the tower. Based on the Egyptian loads code (No. 201) version 2012 [15], the response spectrum for the zafarana zone was constructed. Dynamic analysis based on response spectrum method was implemented in ANSYS, the structural response of the tower in term of its maximum peak values of displacements and forces are presented. 


\section{Nordex N43 Wind Turbine Tower}

The Nordex N43/600 is 3-bladed, horizontal-axis wind turbine with a 43 meter rotor diameter, as shown in Fig. 3. Tubular towers made of steel are constructed by rolling flat steel plates to the desired diameter and welding to join. The supporting tower is a steel conical tower with height of $40 \mathrm{~m}$ which consists of two sections, as shown in Fig. 4. The top and bottom tower diameters are $1.56 \mathrm{~m}$ and $3.178 \mathrm{~m}$; respectively. The thickness of the tower varies from $1.5 \mathrm{~cm}$ at the bottom of the tower to $0.8 \mathrm{~cm}$ at the top. The complete Nacelle weight (including gearbox and generator) is $215 \mathrm{kN}$ and the rotor weight is $140 \mathrm{kN}$. So the total weight mounted at the top of the tower is approximately $355 \mathrm{kN}$.

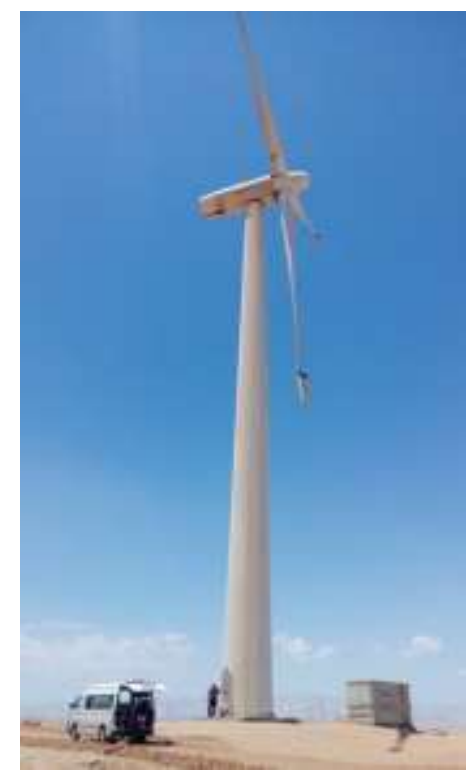

Fig. 3 Typical Nordex N43 wind turbine tower at Zafarana wind farm.

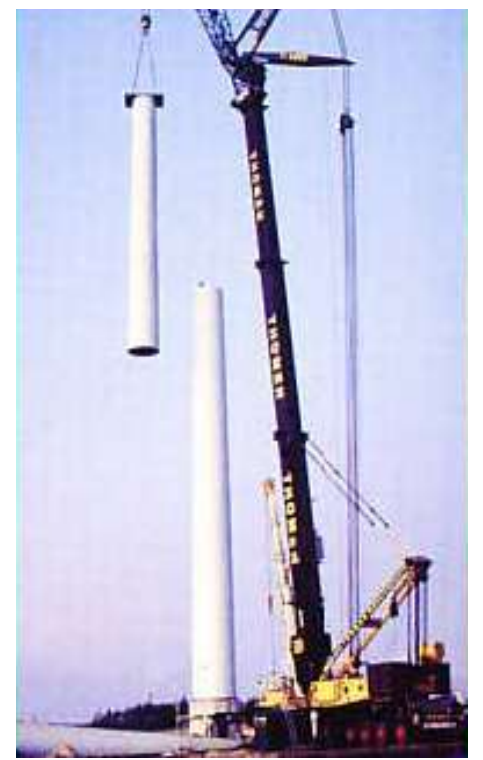

Fig. 4 Nordex N43 tower during construction.

\section{Ambient Vibration Testing}

Ambient vibration testing is also known as output only response modal testing [16:17], as it does not need artificial force input. It mainly uses natural ambient surrounding forces such as winds without having to measure them. Using such technique, only the vibration response of the tower was measured. Three LAN-XI data acquisition modules were distributed along the height of the tower and connected to a network switch with a single LAN cable each as shown in Fig. 5. This supplies both power and assures perfectly sample-synchronized data acquisition. Sixteen highly sensitive accelerometers were used to capture the vibration response of the tower in main horizontal directions Fig. 6. The measuring system encounters PULSE Data Acquisition software for the complete vibration testing solution from Brüel \& Kjær into a cohesive system using Brüel \& Kjær's PULSE LAN-XI modular hardware with dynamic range $160 \mathrm{~dB}$. The measurement on the 40 meter-high wind turbine tower, as shown in Fig. 7, required a measurement time of thirty minutes to acquire simultaneous response measurements in 16 different degrees of freedom (DOFs). Recording 16 channels at $51.2 \mathrm{kHz}$ sampling frequency for 30 minutes produced a file of $1 \mathrm{~GB}$. Extensive details about the field dynamic testing of the tower is published in (G.Saudi \& H.Kamal,2013) [18].

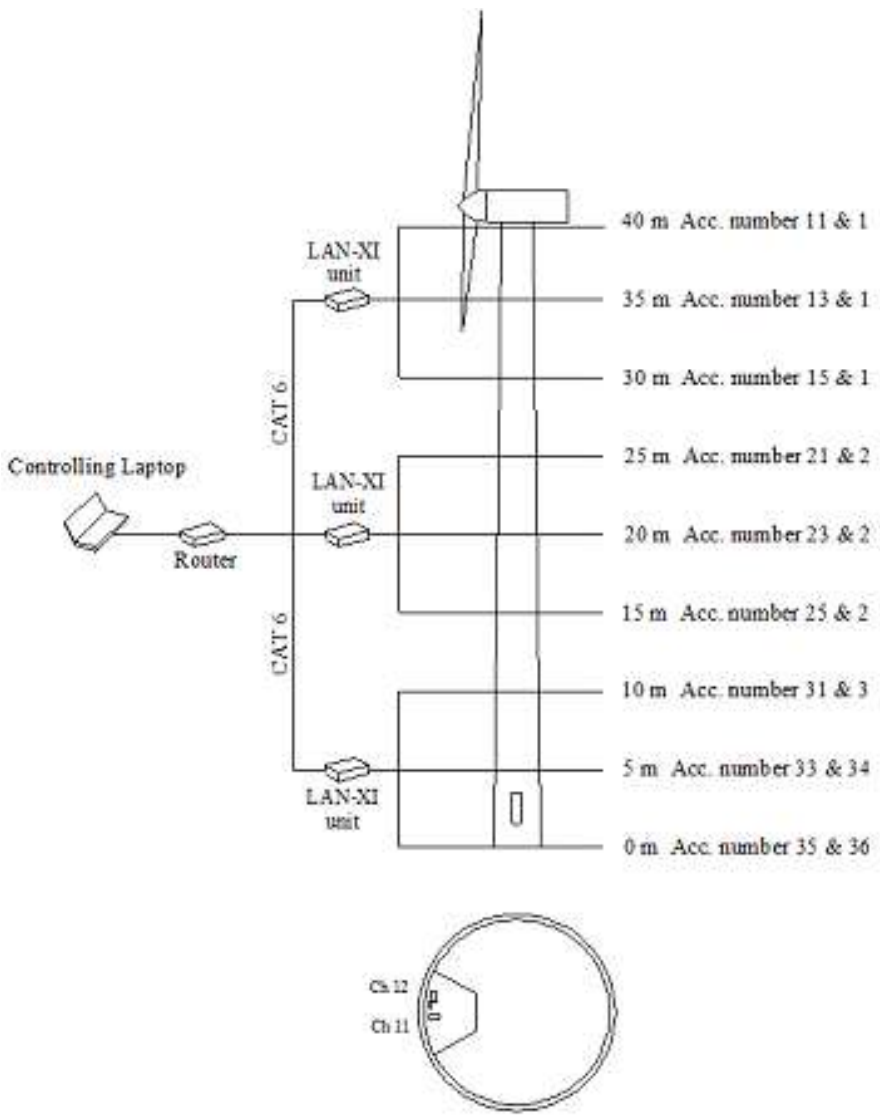

Fig. 5 Test setup for dynamic testing.

\section{Iv. Modal Identification and Validated Finite Element Model}

The experimental modal analysis was performed using ARTeMIS extractor program [19] in two techniques. The first technique was The Enhanced Frequency Domain Decomposition (EFDD) and the other was the Stochastic Subspace Identification (SSI). The modal assurance criterion (MAC) values were computed to study the correlation between the mode shapes obtained for the Nordex wind 
Proc. of Fifth International Conference On Advances in Civil, Structural and Mechanical Engineering -ACSM 2016 Copyright (C) Institute of Research Engineers and Doctors, USA .All rights reserved.

ISBN: 978-1-63248-105-4 doi: 10.15224/ 978-1-63248-105-4-25

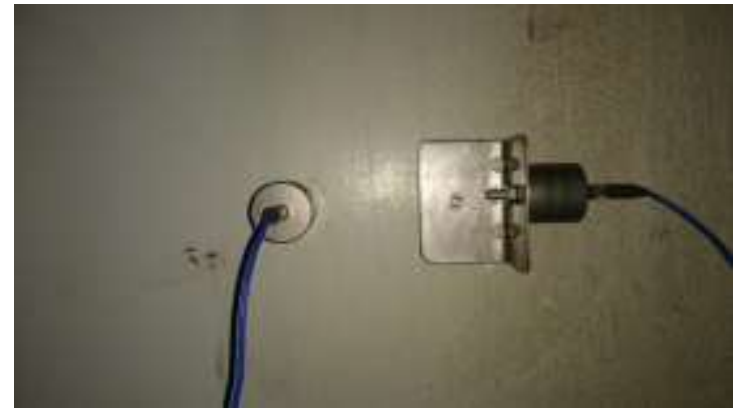

Fig. 6 Set of accelerometers in two main horizontal directions.

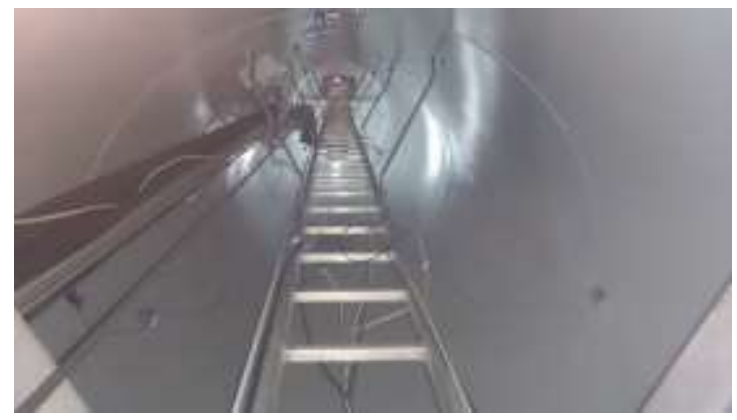

Fig. 7 Mounting accelerometers along the tower height.

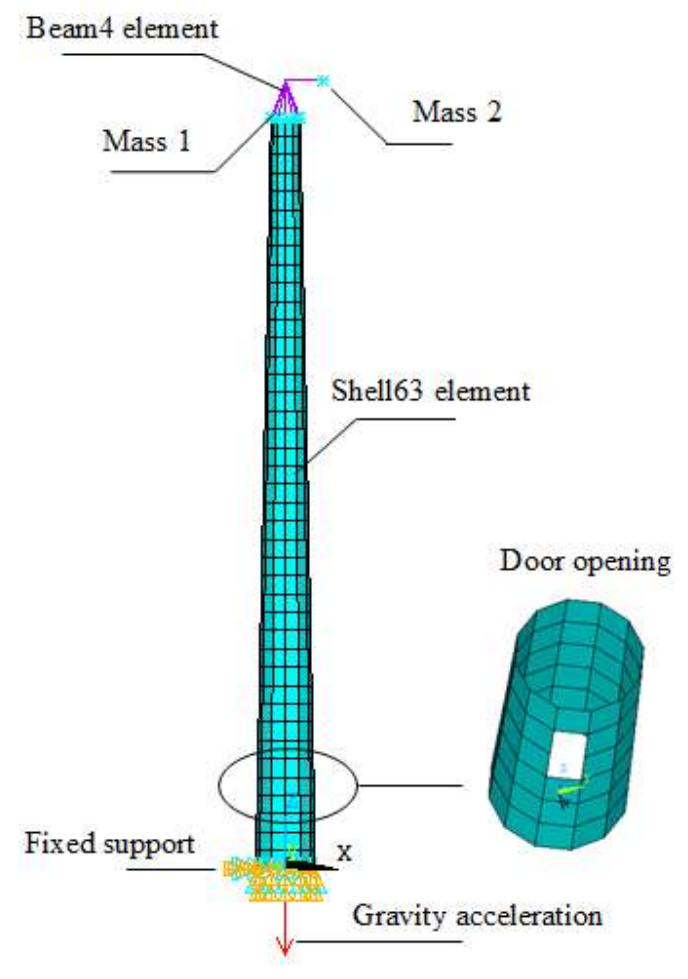

Fig. 8 The updated FE model.
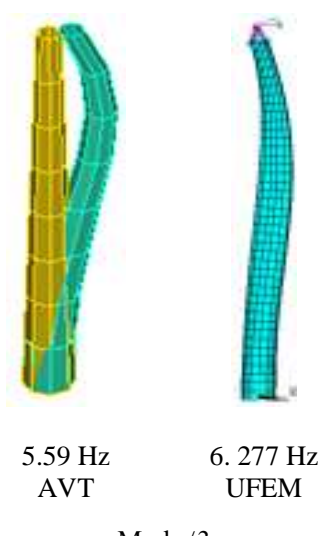

Mode $\neq 2$
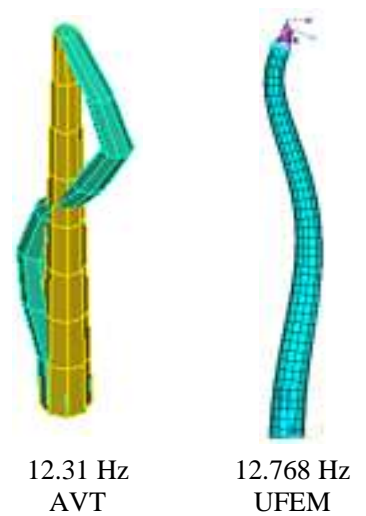

Mode $\neq 6$

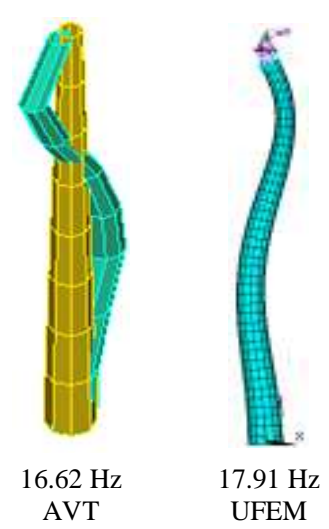

Mode $\neq 7$
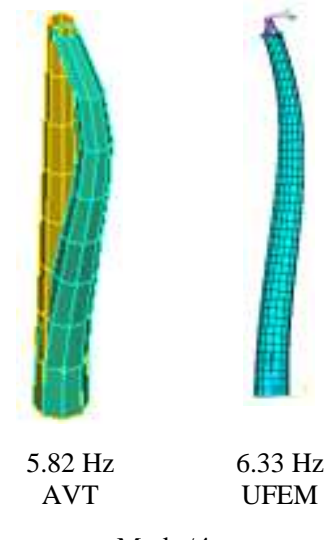

$6.33 \mathrm{~Hz}$

Mode $\neq 4$
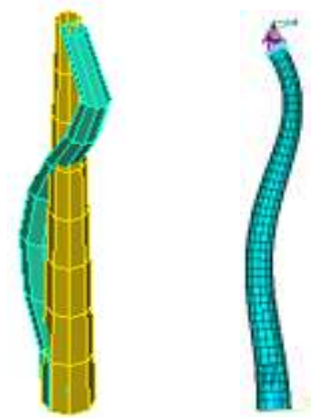
$17.96 \mathrm{~Hz}$
AVT
$17.97 \mathrm{~Hz}$ UFEM

Fig. 9 Experimental and numerical modal analysis of Nordex tower. 
turbine tower using EFDD and SSI methods (G.saudi \& $\mathrm{H}$. Kamal 2013) [18]. The initial FEM of Nordex N43 tower was modified where more elements were introduced to represent the nacelle and rotor parts. Beam4 element was employed to simulate the Nacelle and rotor. The Nacelle was simplified as twelve beams (Beam4) connected to the top of the tower. The hub was represented with a beam connected to the Nacelle and Mass was applied as a concentrated mass at the end of the hub to represent the rotor masses. While the masses of the nacelle and its mechanical components are represented by point masses distributed at the top level of the tower as shown in Fig. 8.

The door opening was simplified as a rectangular void with $2 \mathrm{~m}$ height and $0.70 \mathrm{~m}$ width at a height of $3 \mathrm{~m}$ from the base. The modal analysis of the updated FEM predicted the dynamic behavior of the tower in terms of its modal frequencies and the corresponding mode shapes. Comparison between the results and the experimental findings produced good agreement as shown in Fig. 9 $[16 ; 17]$.

\section{v. Response Spectrum From Egyptian Loads Code Version 2012}

The Egyptian loads code (No. 201) version 2012 [15] includes the general rules to calculate the loads resulting from seismic forces. So, it represents the main code for calculating the seismic response spectrum, the base shear on the structures and the minimum requirements and acceptance of the construction work limits and business buildings in seismic zones. Earthquake loads obtained from the Egyptian code for loads are considered as calculated design loads at the ultimate state [20:21]. The Egyptian loads code (No. 201) version 2012 [15] divides Egypt into five main zones according to the seismic impact. According to this classification Zafarana wind farm is located at the third zone. The design ground acceleration represents the seismic zones considering the assumed returned time of earthquake is 475 year is taken as $0.15 \mathrm{~g}$. (The ground acceleration is considered $9.81 \mathrm{~m} / \mathrm{s} 2$ ).

The soil category at Zafarana wind farm is taken as category (A) representing formations like rock have very high SPT results [17]. According to the Egyptian loads code (No. 201) version 2012 [15], the structures can be designed on seismic loads less than what is designed to the flexible response spectrum as a result of the structural system ability to dissipate energy through the occurrence of plastic formations. The horizontal design spectrum $\mathrm{Sd}(\mathrm{T})$ can be determined for the fundamental period of the buildings as following:

$$
\begin{gathered}
0 \leq \mathrm{T}_{1} \leq \mathrm{T}_{\mathrm{B}} \quad: \mathrm{S}_{\mathrm{d}}(\mathrm{T})=\mathrm{a}_{\mathrm{g}} \gamma_{\mathrm{I}} \mathrm{S}\left[\frac{2}{3}+\frac{\mathrm{T}}{\mathrm{T}_{\mathrm{B}}}\left(\frac{2.5}{\mathrm{R}}-\frac{2}{3}\right)\right] \\
\mathrm{T}_{\mathrm{B}} \leq \mathrm{T}_{\mathrm{I}} \leq \mathrm{T}_{\mathrm{C}} \quad: \mathrm{S}_{\mathrm{d}}(\mathrm{T})=\mathrm{a}_{\mathrm{g}} \gamma_{\mathrm{I}} \mathrm{S} \frac{2.5}{\mathrm{R}} \\
\mathrm{T}_{\mathrm{C}} \leq \mathrm{T}_{\mathrm{I}} \leq \mathrm{T}_{\mathrm{D}} \quad: \mathrm{S}_{\mathrm{d}}(\mathrm{T})=\mathrm{a}_{\mathrm{g}} \gamma_{\mathrm{I}} \mathrm{S} \frac{2.5}{\mathrm{R}}\left[\frac{\mathrm{T}_{\mathrm{C}}}{\mathrm{T}}\right] \geq 0.20 \mathrm{a}_{\mathrm{g}} \gamma_{\mathrm{I}} \\
\mathrm{T}_{\mathrm{D}} \leq \mathrm{T}_{\mathrm{I}} \leq 4 \sec \quad: \mathrm{S}_{\mathrm{d}}(\mathrm{T})=\mathrm{a}_{\mathrm{g}} \gamma_{\mathrm{I}} \mathrm{S} \frac{2.5}{\mathrm{R}}\left[\frac{\mathrm{T}_{\mathrm{C}} \mathrm{T}_{\mathrm{D}}}{\mathrm{T}^{2}}\right] \geq 0.20 \mathrm{a}_{\mathrm{g}} \gamma_{\mathrm{I}}
\end{gathered}
$$

Where:

Sd (T) : Horizontal design spectrum.

$\mathrm{T}_{1}$ : Fundamental period of the structure.

S: Soil factor.

$\mathrm{T}_{\mathrm{B}}, \mathrm{T}_{\mathrm{C}}$ : Constant limits for the elastic response spectrum.

$\mathrm{T}_{\mathrm{D}}$ : The absolute value for the beginning of constant displacement.

$\mathrm{a}_{\mathrm{g}}$ : Design ground acceleration.

$\gamma_{\mathrm{I}}$ : The structure importance factor.

R: Response Modification (Force Reduction) Factors.

The soil components $\left(\mathrm{S}, \mathrm{T}_{\mathrm{B}}, \mathrm{T}_{\mathrm{C}}, \mathrm{T}_{\mathrm{D}}\right)$ are determined according to the category of soil and the type of response spectrum (TABLE I). According to the Egyptian loads code (No. 201) version 2012 [15], the facilities, that have to efficiently operate during and beyond the earthquake and use for emergency purposes, have a great importance factor as 1.40 which was assigned to wind turbine structures in Zafarana wind farm. Response Modification (Force Reduction) Factors (R) are ratios between the generated elastic forces to the generated plastic forces in the structure. It depends on the structure statical system and the members resisting the horizontal loads. The Egyptian loads code (No. 201) version 2012 [15] has not a specific value for the response modification factor of wind turbine towers. The factor for Chimneys and silos is used in this research as the wind tower factor because of the similarity in statical system. Response modification factor is considered as 3.50.

TABLE I.

THE SOIL COMPONENTS ACCORDING TO RESPONSE SPECTRUM

\begin{tabular}{|c|c|c|c|c|}
\hline Subsoil Class & S & TB & TC & TD \\
\hline A & 1.0 & 0.05 & 0.25 & 1.2 \\
\hline
\end{tabular}

The design response spectrum for the wind turbine towers is obtained according to the previous suggested data and depicted in Fig. 13.This response spectrum was used to study the seismic behavior of wind turbine towers.

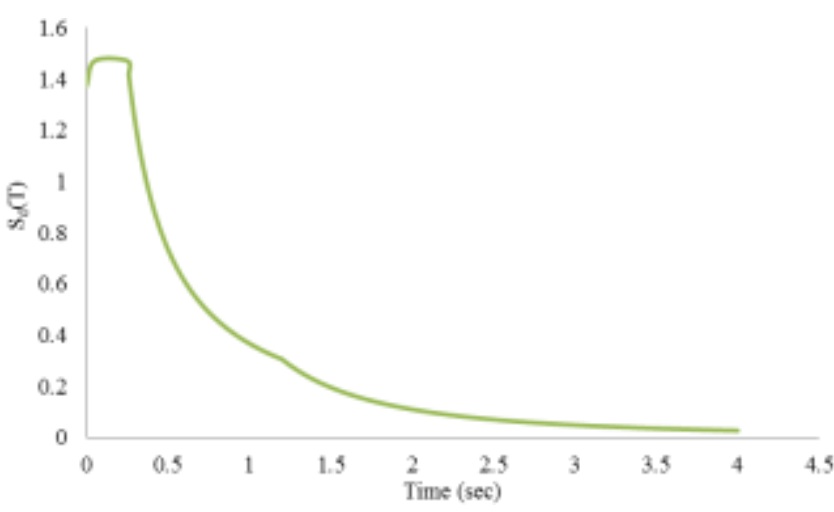

Fig. 10 Design response spectrum for wind towers according to the Egyptian code for loads 2012 (No. 201). 


\section{vi. Results of Seismic Response Spectrum Analysis}

In ANSYS V12 software [14], the obtained response spectrum is applied to FEM through a multiple-point method. Response spectrum is applied at tower base nodes. Response spectrum analysis was performed in $\mathrm{X}$ and $\mathrm{Y}$ directions separately. A constant damping ratio of $2.5 \%$ is used as the response damping according to steel tubular towers. Total of 100 modes was considered in the analysis to satisfy modal mass contribution. The results are obtained at several nodes and elements. Node 1 represents the hub in $\mathrm{X}$ direction and Node 2 represents the hub in Y-direction at a height of $42 \mathrm{~m}$ for Nordex tower as shown in Fig. 11. Node 3 and Node 4 at the middle of Nordex tower at a height of $20 \mathrm{~m}$. The maximum displacement is found at Node1 and Node 2. Maximum stresses located at the door level of the tower, $4 \mathrm{~m}$ from the base. Section 1 represent the elements around the door of the towers where the maximum stresses are in $\mathrm{X}$ and $\mathrm{Y}$ directions. The maximum displacement and stresses obtained from response spectrum for Nordex N43 FEM are shown in TABLE II.

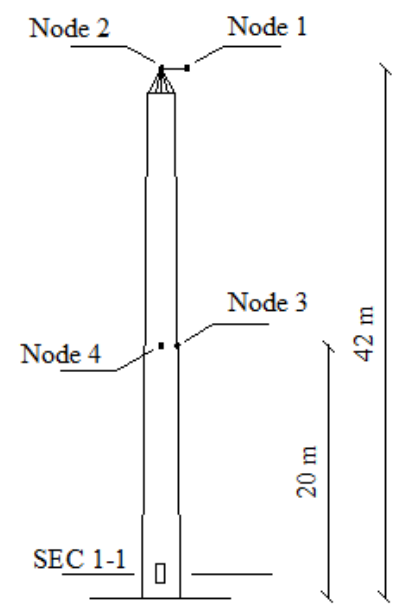

Fig. 11 Location of selected nodes and elements for spectrum analysis.

TABLE II.

MAXIMUM DISPLACEMENT AND STRESS AS OBTAINED FROM RESPONSE SPECTRUM FOR NORDEX N43 UFEM.

\begin{tabular}{|c|c|c|}
\cline { 2 - 3 } \multicolumn{1}{c|}{} & X - direction & Y - direction \\
\hline Maximum Hub Displacement (mm) & 12.76 & 12.77 \\
\hline Middle Displacement (mm) & 2.39 & 2.44 \\
\hline Maximum Stress at Door Level ( N/m2) & $4.01 \times 106$ & $3.94 \times 106$ \\
\hline
\end{tabular}

\section{vII. Conclusions}

This work presents one of the pioneer studies concerning the investigation of the structural dynamic performance of a full-scale wind turbine tower under seismic load in Egypt. Both ambient vibration test at site and numerical modeling using advanced modules were used in this study. The seismic response of the tower was investigated using a response spectrum obtained from the Egyptian loads code (No. 201) version 2012. Both the displacement and stresses at key points along the height of the tower were presented. The conclusions from the current study can be summarized as below:-

1. The zone of the tower around the opening door is the most affected where the stresses were found to be higher than other tower parts. This highlights the importance of careful design of the tower at such zone where concentration of stresses is highly expected.

2. Having all the data being realistic from structural field testing and current seismic records in region of red sea, more confidence in the obtained results was gained. Accordingly the final updated model of the tower represents a reliable baseline model that can be utilized in further structural studies under different loading conditions including wind loads.

3. The Egyptian loads code (No. 201) version 2012 gives almost good simulation for the seismic loads that can be applied to wind turbine tower considering the approach of wind tower parameters to chimney ones.

\section{Acknowledgments}

The authors are grateful to the Science \& Technology Development Fund in Egypt (STDF) for funding this research project in the context of ongoing joint US- Egypt research "Seismic risk assessment of wind turbine towers in Zafarana wind farm Egypt", Project ID:4588. Results shown here are part of the work performed in 2 nd progress report.

\section{References}

[1] Det Norske Veritas and Ris $\varnothing$ National Laboratory, Guidelines for Design of Wind Turbines, 2nd Ed., Det Norske Veritas, Denmark, 2002.

[2] Germanischer Lloyd (GL), Rules and Guidelines, IV -Industrial Services, Part 1 - Guideline for the Certification of Wind Turbines, GL WindEnergie GmbH, Hamburg, Germany, 2003.

[3] International Electrotechnical Commission (IEC), Wind Turbines Part 1: Design Requirements, 3rd Ed., IEC 61400-1:2005-08, IEC, Geneva, Switzerland, 2005.

[4] Canadian Standard Association (CSA), Wind Turbines - Part 1: Design Requirements, CAN/CSA C61400-1:08, CSA, Toronto, Canada, 2008

[5] E. A. Bossanyi, "GH Bladed theory manual," 282/BR/009, Garrad Hassan and partners Limited, Bristol, UK, December 2003.

[6] N. Bazeos, G. Hatzigeorgiou, I. Hondros, H. Karamaneas, D. Karabalis, and D. Beskos, "Static, seismic and stability analyses of a prototype wind turbine steel tower," Journal of Engineering Structures, Vol. 24, No. 8, pp. 1015-1025, 2002.

[7] I. Lavassas, G. Nikolaidis, P. Zervas, E. Efthimiou, I. N. Doudoumis, and C. C. Baniotopoulos, "Analysis and design of the prototype of a steel 1-MW wind turbine tower," Journal of Engineering Structures, Vol. 25, No. 8, PP. 1097-1106, July 2003.

[8] O. Kiyomiya, T. Rikiji, and P. H. A. J. M. van Gelder, "Dynamic response analysis of onshore wind energy power units during earthquakes and wind," Proceedings of the 12nd International Offshore and Polar Engineering Conference, Kitakyushu, Japan. The International Society of Offshore and Polar Engineers, PP. 520-526, May 2002.

[9] U. Ritschel, I. Warnke, J. Kirchner, and B. Meussen, "Wind turbines and earthquake," WWEC, The second World Wind Energy Conference and Renewable Energy, Cape Town, South Africa, November 2003.

[10] I. Prowell, M. Veletzos, A. ELGamal, and J. Restrepo, "Experimental and numerical seismic response of a $65 \mathrm{~kW}$ wind turbine," Journal of Earthquake Engineering, Vol. 13, pp. 1172-1190, 2009.

[11] A. T. Myers, A. Gupta, C. M. Ramirez, and E. Chioccarelli, "Evaluation of the seismic vulnerability of tubular wind turbine 
towers," 15WCEE, 15th World Conference on Earthquake Engineering, European Wind Energy Association, Lisbon, Portugal, July 2012.

[12] M. Hongwang, "Seismic analysis for wind turbines including soilstructure interaction combining vertical and horizontal earthquake," 15WCEE, 15th World Conference on Earthquake Engineering, European Wind Energy Association, Lisbon, Portugal, July 2012.

[13] F. Taddei, and K. Meskouris, "Seismic analysis of onshore wind turbine including Soil-Structure Interaction effects," SeDIF, International Conference on Seismic Design of Industrial Facilities, Aachen, Germany, September 2013.

[14] ANSYS, User's manual, revision 12.00 ANSYS, Inc., 2012.

[15] The Egyptian loads code, No. 201, Housing and Building National Research Center, Egypt, 2012.

[16] K. Kandil, G. Saudi, B. Eltaly, and M. M. Abo El-Khier, "Seismic response of a full-scale wind turbine tower using experimental and numerical modal analysis," International Journal of Advanced Structural Engineering, in press.

[17] M. M. Abo El-Khier, "Simulating the dynamic behavior of the wind turbine tower using ambient vibration testing," MSc thesis, Civil Engineering Department, Faculty of Engineering, Menoufia University, Menoufia, Egypt, 2015.

[18] G. Saudi, and H. Kamal, "Ambient vibration testing of full- scale wind turbine tower," the 10th International Conference on the Role of Engineering Towards A Better Environment Intelligent Environmental Engineering: From Vision to Action, Alexandria, Egypt, December, 2014.

[19] ARTeMIS Extractor, Structural Vibration Solutions A/S: Operational Modal Analysis, 2012.

[20] K. Abdel-Raheem, S. Abdel Raheem, H. Soghair, and M. Ahmed, "Evaluation of seismic performance of multistory buildings designed according to Egyptian Code," Journal of Engineering Sciences, Assiut University, Vol. 38, No. 2, pp. 381-402, March 2010.

[21] S. Mahmoud, and W. Abdallah, "Response analysis of multi-story RC buildings under equivalent static and dynamic loads according to egyptian code," International Journal of Civil and Structural Engineering Research, Vol. 2, No. 1, pp. 79-88, March 2014.

About Author (s):

Dr. Ghada N. Saudi

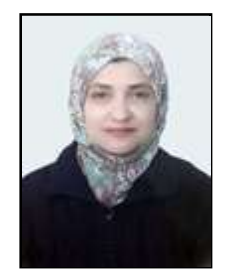

This research work is one of the pioneer studies for investigating wind turbine towers in Egypt for their structural seismic response in Zafarana wind farm

Dr. Boshra Aboul-Anen Eltaly

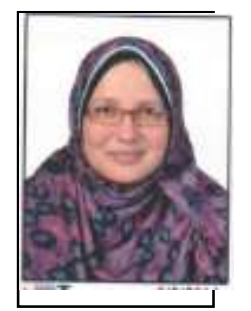

Ansys is a powerful program for dynamic analysis of different structures. The numerical model in Ansys produced modal results in good agreement with the measured counterparts. Thus reliable structural analysis was obtained

Eng. Mostafa Mahmoud Abo El-khier

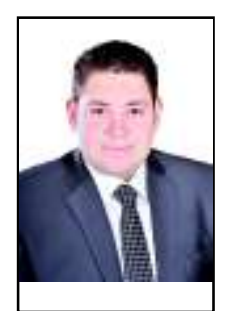

Applying field dynamic testing on large structures as wind turbine towers is quite challenging. However, the ambient vibration techniques AVT efficiently identified the modal behavior of these towers. 